\title{
ОСОБЕННОСТИ КУЛЬТУРЫ ОТНОШЕНИЙ МЛАДШИХ ШКОЛЬНИКОВ В УСЛОВИЯХ ИНКЛЮЗИВНОГО ОБРАЗОВАНИЯ
}

\section{FEATURES OF THE CULTURE OF RELATIONS BETWEEN PRIMARY SCHOOL CHILDREN IN THE CONTEXT OF INCLUSIVE EDUCATION}

V. Myagkova

Summary: In this article, the concept of "relationship culture» is considered from the point of view of inclusive education of primary school children. The author presents his own experience of studying the culture of relations in the context of inclusion. The purpose of the article is an experimental test of the culture of relationships of primary school children in the conditions of inclusive education. The author comes to the conclusion that the culture of younger schoolboys in the conditions of inclusion is low, and highlights the main areas of work to improve the culture of younger schoolchildren in the society.

Keywords: relationship culture, interpersonal relationships, inclusion, inclusive education, primary school students.

\author{
Мягкова Виктория Вячеславовна \\ Аспирант, Московский городской педагогический \\ университет \\ myagkowa.viktoriya@yandex.ru
}

Аннотация: В данной статье понятие «культура отношений» рассматривается с точки зрения инклюзивного обучения младших школьников. Представлен собственный опыт исследования культуры отношений в условиях инклюзии. Целью статьи является экспериментальная проверка культура взаимоотношений младших школьников в условиях инклюзивного образования. Автор приходит к выводу, что культура отношений младших школьников в условиях инклюзии находится на низком уровне, а также выделяет основные направления работы, способствующие повышению культуры взаимоотношений младших школьников в социуме.

Ключевые слова: культура отношений, межличностные отношения, инклюзия, инклюзивное образование, младшие школьники.

ствующие методы педагогической работы. Это определило актуальность нашего исследования.

Целью исследования является экспериментальная проверка психолого-педагогических условий формирования культуры взаимоотношений обучающихся младшего школьного возраста в условиях инклюзивного образования.

Экспериментальное исследование культуры отношений младших школьников было организовано на базе двух государственных образовательных учреждений г. Москвы: ГБОУ «Лицей №1574 ОП-3» и ГБОУ «Школа Глория» с сентября 2015 года по май 2021 года.

В исследовании приняли участие 96 обучающихся начальных классов. В указанную выборку входят 27 учеников с ограниченными возможностями здоровья с различными видами нарушений (детский церебральный паралич - 1 чел., расстройство аутистического спектра - 5 чел., задержка психического развития - 9 чел., тяжелые нарушения речи - 8 чел, умственная отсталость - 4 чел.), получающие образование в условиях инклюзивного обучения. Для чистоты эксперимента в выборке участвовали по два параллельных класса из разных школ (ЭГ-1, ЭГ-2 - экспериментальные группы; КГ-1, КГ-2 - контрольные группы).

Была организована работа по оценке состояния теку- 
щего уровня сформированности культуры отношений у младших школьников, посредством применения диагностических методик, включенного наблюдения и бесед.

В структурном содержании культуры отношений младших школьников было выделено 3 компонента: коммуникативная культура, культура поведения и культура речи. Данные компоненты послужили критериями для определения состояния культуры взаимоотношений.

В рамках исследования была проведена диагностика каждого выделенного компонента культуры отношений. При подборе диагностических методик для оценки состояния у младших школьников культуры отношений, учитывались возможности определения культурных аспектов, возможности определения ценностных и моральных установок школьников.
Для оценки состояния культуры отношений у младших школьников были использованы следующие методики:

1. Тест «Оценка общительности» (модифицированный вариант методики В.Ф. Ряховского) [1, с. 34],

2. Задание «Рукавички» (Г.А. Цукерман) [6, с. 68],

3. Модифицированный вариант методики «Архитектор-строитель» [4, с. 43],

4. Диагностическая методика «Сюжетные картинки» (модифицированный вариант Р.Р. Калининой) $[3$, c. 21].

Анализ результатов исследования, показал, что большая часть всех учеников, обучающихся в условиях инклюзивного образования, имеют низкий и средний уровни культуры отношений, при этом количество детей с высоким уровнем культуры отношений ни в одной

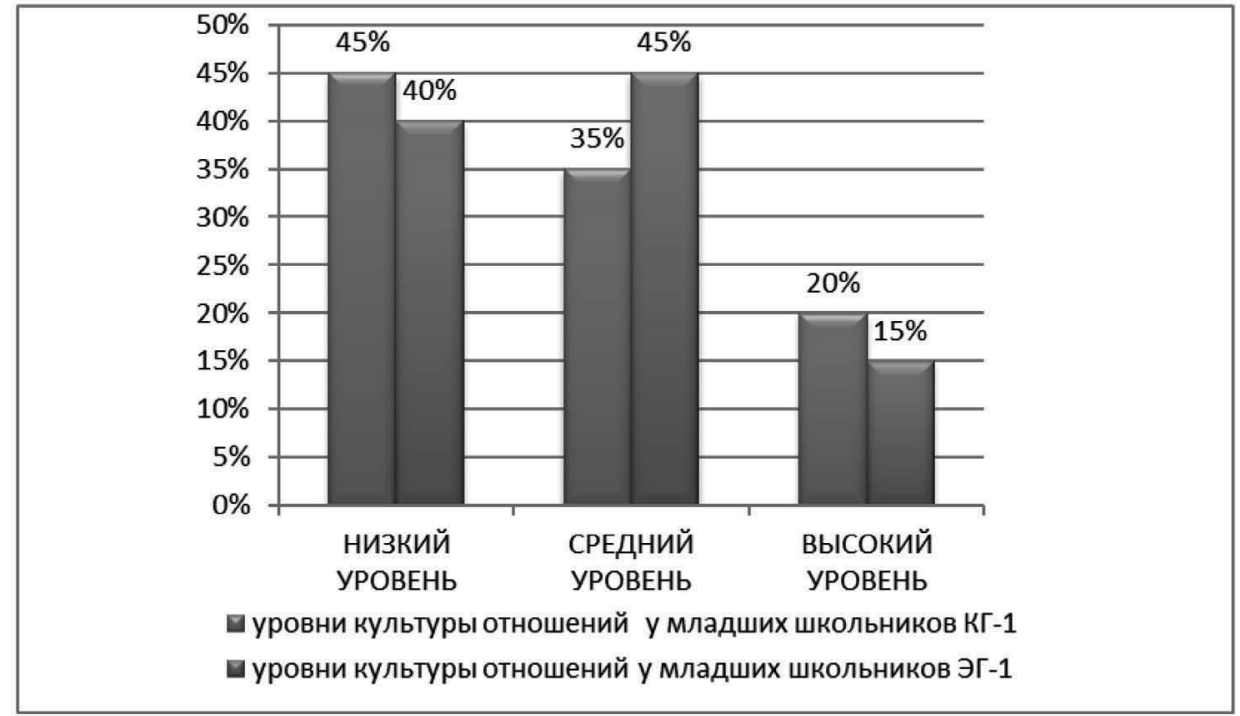

Рис. 1. Уровень культуры отношений у групп КГ-1 и ЭГ-1 на констатирующем этапе эксперимента

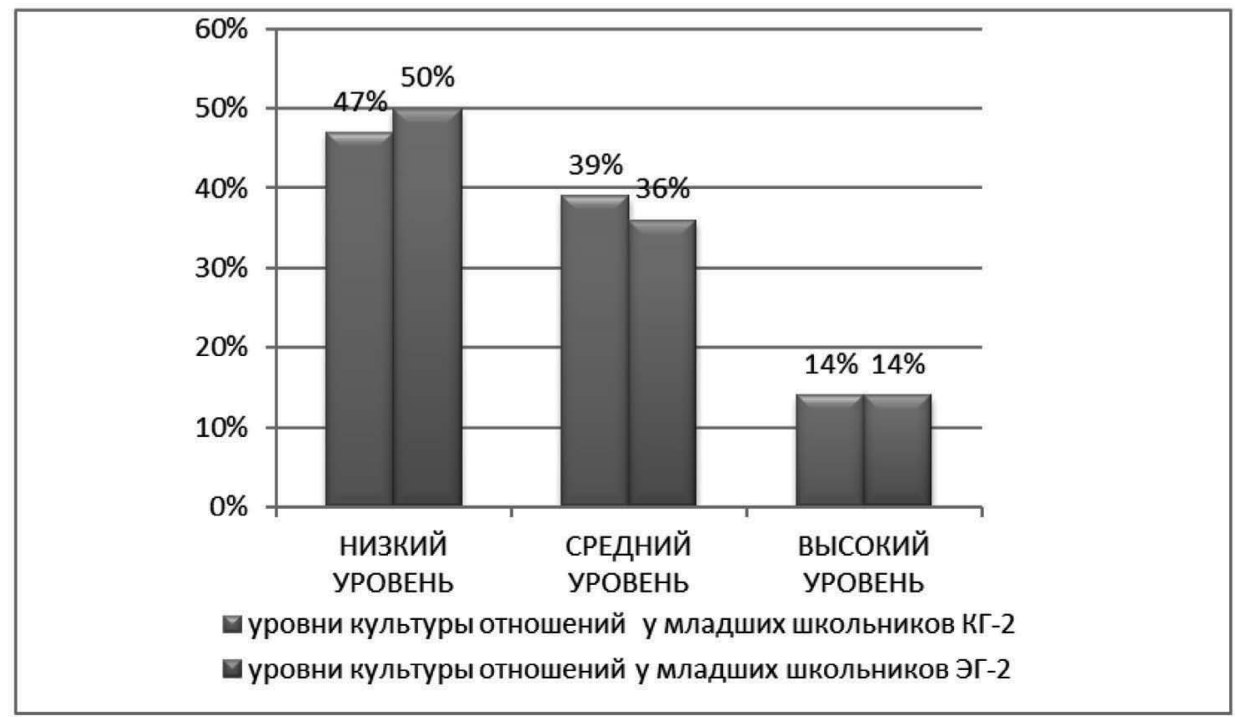

Рис. 2. Уровень культуры отношений у групп КГ-2 и ЭГ-2 


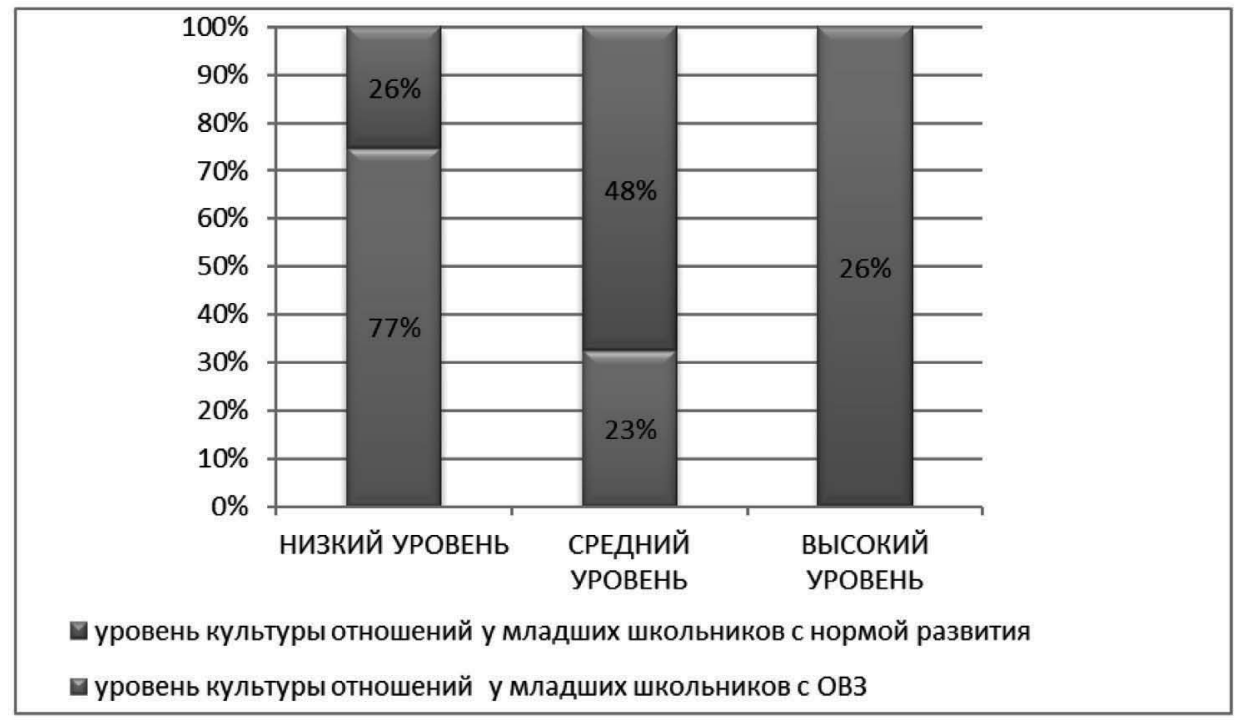

Рис. 3. Сравнительная характеристика состояния культуры отношений детей с ОВЗ и других учащихся у групп КГ-1 и ЭГ-1

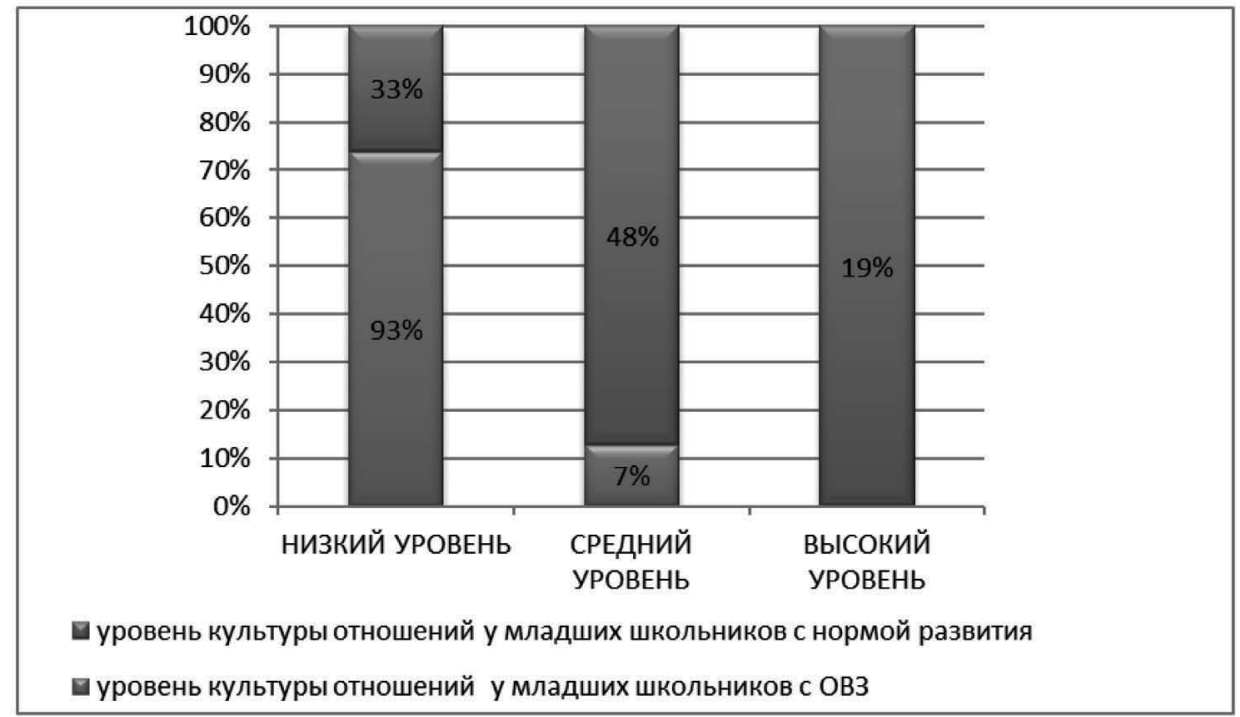

Рис. 4. Сравнительная характеристика состояния культуры отношений детей с ОВЗ и других учащихся у групп КГ-2 и ЭГ-2

группе не превышает 20\% обучающихся (рис.1, 2).

У $85 \%$ обучающихся с ОВ3 был выявлен низкий уровень сформированности культуры отношений. При этом у обучающихся с ОВЗ не выявлен высокий уровень сформированности культуры отношений (рис. 3,4$)$.

Результаты, полученные в ходе исследования, позволяют оценить, какие нормы и правила культуры отношений и поведения уже освоены каждым ребенком, а какие необходимо формировать.

Было установлено, что культура отношений младших школьников в условиях инклюзивного образования находится преимущественно на низком уровне. Это обуславливает необходимость организации целенаправленной специальной работы по формированию культуры отношений у младших школьников.
Были выделены основные направления работы:

1. Социально-педагогическое направление предполагает оказание адресной дифференцированной помощи всем субъектам образовательной деятельности.

2. Программно-структурное направление включает организацию и содержательную разработку последовательных этапов по психолого-педагогическому сопровождению участников образовательной деятельности.

3. Комплекс мероприятий по формированию культуры отношений, включающий в себя тьюториалы (индивидуальные программы обучения), тренинги, игровые занятия, проведение различных мероприятий (в том числе КТД), игр, подбор индивидуальных заданий. 


\section{ЛИТЕРАТУРА}

1. Абдуллаева М.М. Тест общительности. В.Ф. Ряховский // Психология общения. Энциклопедический словарь. / Под ред. А.А. Бодалева. - 2-е изд., испр. и доп. - М.: Когито-Центр, 2015. - 671 с.

2. Богданова Т.Г., Назарова Н.М. Особые образовательные потребности как основа выбора и использования образовательных технологий / Т.Г. Богданова, Н.М. Назарова // Понятийный аппарат педагогики и образования: коллективная монография. - [Отв. ред.: Е. В. Ткаченко, М. А. Глазунова]. - Екатеринбург, 2017. - 352 c.

3. Калинина Р.Р. Психолого-педагогическая диагностика в детском саду / Р.Р. Калинина. - М.: Речь, 2011. - 144 с.

4. Лидерс А.Г. Психологическое обследование семьи: Учебное пособие-практикум для студентов факультета психологии ВУз / А.Г. Лидерс. - 2-е изд. М.: Академия, 2007. -432 c.

5. Лубовский В.И. Специальная психология / В.И. Лубовский, Т.В. Розанова, Л.И. Солнцева; под ред. В.И. Лубовского. - М.: Академия, 2014. - 428 с.

6. Цукерман Г.А. Что развивает и чего не развивает учебная деятельность младших школьников / Г.А. Цукерман // Вопросы психологии. - 1998. № 5. - C. 68-81.

(с) Мягкова Виктория Вячеславовна (myagkowa.viktoriya@yandex.ru).

Журнал «Современная наука: актуальные проблемы теории и практики»

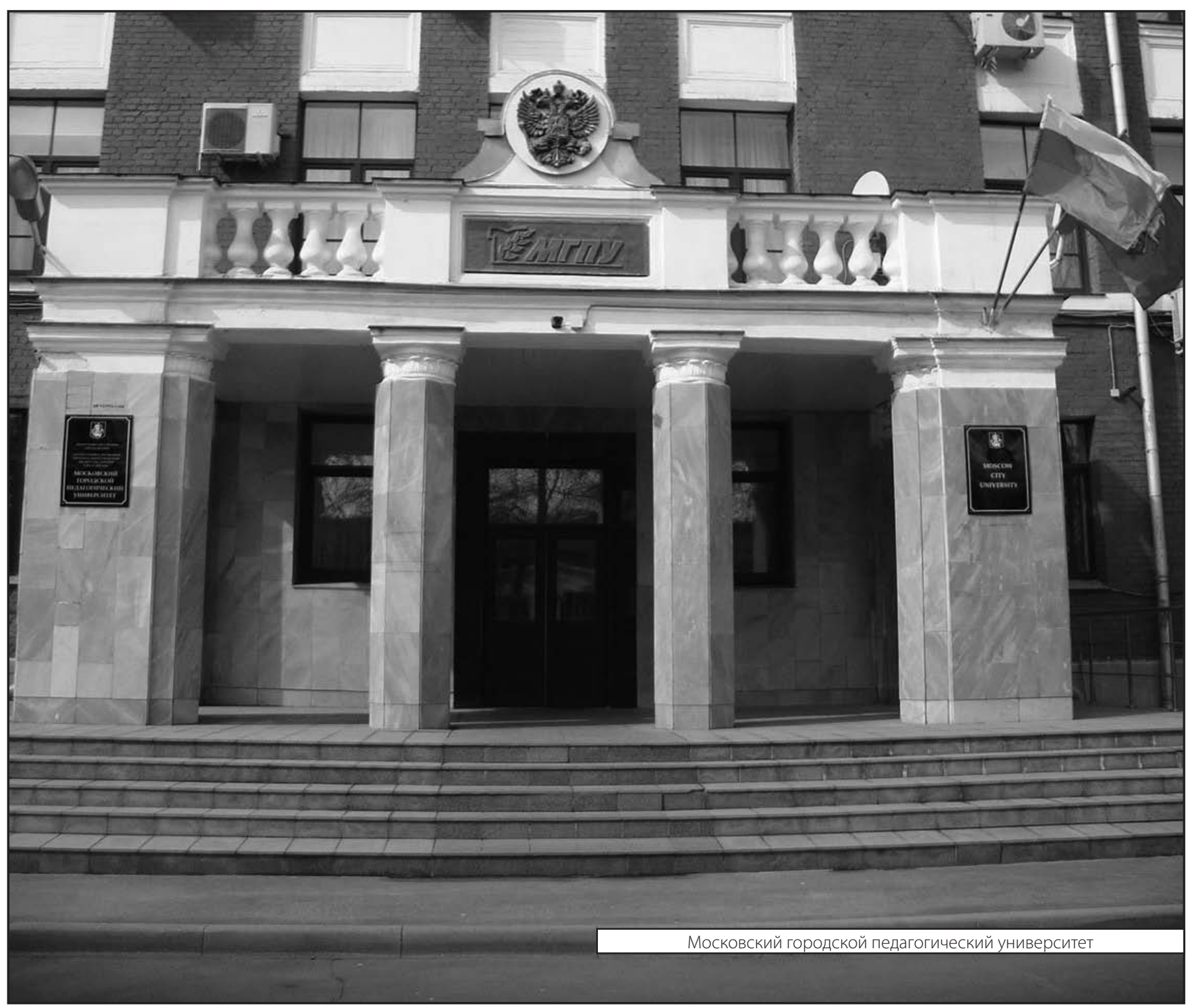

